\title{
Using Artificial Neural Network to Predict the Compressive Strength of Concrete containing Nano-silica
}

\author{
Sakshi Gupta \\ Department of Civil Engineering, Dronacharya College of Engineering, Gurgaon, Haryana, India \\ *Coresponding Author: dceggnsakshigupta@gmail.com
}

Copyright $@ 2013$ Horizon Research Publishing All rights reserved.

\begin{abstract}
This paper presents application of artificial neural network to develop model for predicting 28 days compressive strength of concrete with partial replacement of cement with nano-silica for which the data has been taken from various literatures. The use of nano-particle materials in concrete can add many benefits that are directly related to the durability of various cementitious materials, besides the fact that it is possible to reduce the quantities of cement in the composite. The performance of the model can be judged by the correlation coefficient, mean absolute error and root mean square error have been adopted as the comparative measures against the experimental results obtained from the literature.
\end{abstract}

Keywords Artificial Neural Network, Nano-Silica, Concrete, Compressive Strength, Partial Replacement

\section{Introduction}

Concrete is one of the oldest materials in the construction industry which is a mixture of paste and aggregates. Concrete production is a complex process that involves the effect of several processing parameters on the quality control of concrete pertaining to workability, strength etc. These parameters are all effective in producing a single strength quantity of compressive strength. Nanotechnology creates new possibilities to improve material properties for civil construction. Attracting civil engineers to adopt nanotechnology could enable them to provide pioneering solution to the complex problems of construction today. It is well known that materials such as concrete; are the core elements of construction industry and these materials could be developed by using nanotechnology. Nanosilica is typically a highly effective pozzolanic material. It normally consists of very fine vitreous particles approximately 1000 times smaller than the average cement particles. It has proven to be an excellent admixture for cement to improve strength and durability and decrease permeability [1]. Thus, the rank of application of nanotechnology in construction is ranging from eight to ten for the applications that most likely have impact in the developing world [2].

The present study was envisaged to develop a relation between various input parameters and an output parameter i.e. 28 days compressive strength, using ANN technique. The objective was to study the application of artificial neural network for predicting the 28-day compressive strength of concrete containing nano-silica which is partial replacement of cement, with data obtained from literature.

Over the last two decades, different data mining methods such as the fuzzy logic and artificial neural network, have become popular and have been used by many researchers for a variety of engineering applications. In daily life, information obtained is used to understand the surroundings to imbibe new things and to make plans for the future. Over the years, the ability to reason has been developed on the basis of evidence available to achieve the required goals. To deal with the problem of uncertainty, the theory of probability had been established and successfully applied to many areas of engineering and technology [3-6].

\section{Artificial Neural Network (ANN)}

Study on artificial neural networks has been motivated right from its inception by the recognition that the brain computes in an entirely different way from the conventional digital computer. A neural network is a massively parallel distributed processor that has a natural propensity for storing experiential knowledge and making it available for use. It resembles the brain in two respects:

1. Knowledge is acquired by the network through a learning process.

2. Interneuron connection strengths known as synaptic weights are used to store the knowledge.

The procedure used to perform the learning process is called a learning algorithm. The use of ANN offers the following useful properties and capabilities:

Non-linearity

Input-output mapping

Adaptivity

Contextual information

Uniformity of analysis and design 
A Multi-layer perceptron (MLP) consists of multiple layers of nodes in a directed graph, with each layer fully connected to the next one. Except for the input nodes, each node is a neuron (or processing element) with a nonlinear activation function. MLP utilizes a supervised learning technique called back propagation for training the network. MLP is a modification of the standard linear perceptron and can distinguish data that is not linearly separable. The main advantage of ANNs is that one does not have to explicitly assume a model form, which is a pre-requisite in the parametric approach. It does not need any specific equation form. ANN automatically manages the relationships between variables and adapt based on the data used for their training. So it is important to collect a large number of experimental data to carry out the modelling of the system.

The accuracy of the predictions of a network was quantified by the root of the mean squared error difference (RMSE), between the measured and the predicted values, mean absolute error (MAE): the same as root mean square except using absolute differences instead of squared difference and the multiple coefficient of determination which compares the accuracy of the model with the accuracy of a superficial benchmark model wherein the prediction is the mean of all samples.

In this study, multilayer perceptron (MLP): a feed forward artificial neural network model is implemented. A large test database has been extensively surveyed and collected. It is then carefully examined to establish the input vectors and the desired output vectors. Finally, a new model is proposed based on ANN and then verified against experimental data which has been collected from different sources [7-16].

Table 1. Details of data used in modelling

\begin{tabular}{|c|c|c|c|c|c|c|c|c|c|}
\hline S.No & $\begin{array}{l}\text { Cement } \\
(\mathrm{kg} / \mathrm{m} 3)\end{array}$ & $\begin{array}{c}\text { FA } \\
(\mathrm{kg} / \mathrm{m} 3)\end{array}$ & $\begin{array}{c}\mathrm{CA} \\
(\mathrm{kg} / \mathrm{m} 3)\end{array}$ & $\begin{array}{l}\text { W/b } \\
\text { Ratio }\end{array}$ & $\begin{array}{c}\mathrm{SP} \\
(\mathrm{kg} / \mathrm{m} 3)\end{array}$ & $\begin{array}{c}\mathrm{nS} \\
(\mathrm{kg} / \mathrm{m} 3)\end{array}$ & $\begin{array}{c}\text { D } \\
(\mathbf{n m})\end{array}$ & $\begin{array}{r}\text { 28-d CS } \\
\text { (MPa) }\end{array}$ & $\begin{array}{c}\text { Researcher } \\
\text { (Year) }\end{array}$ \\
\hline 1 & 396.6 & 826 & 722 & 0.37 & 7 & 16.5 & 15 & 75.2 & \multirow[t]{3}{*}{ Morteza H. Beigi et al. (2013) } \\
\hline 2 & 380 & 826 & 722 & 0.35 & 7 & 33 & 15 & 86.1 & \\
\hline 3 & 363.5 & 826 & 722 & 0.33 & 7 & 49.6 & 15 & 85.4 & \\
\hline 4 & 318.4 & 840 & 1040 & 0.5 & 2.71 & 1.6 & 15 & 36.8 & \multirow[t]{2}{*}{ Ali Heidari (2013) } \\
\hline 5 & 316.8 & 840 & 1040 & 0.5 & 4.75 & 3.2 & 15 & 40.2 & \\
\hline 6 & 390 & 783 & 1175 & 0.4 & 1.78 & 23.4 & 35 & 70 & \multirow[t]{4}{*}{ A.M. Said et al. (2012) } \\
\hline 7 & 390 & 774 & 1162 & 0.4 & 3.56 & 46.8 & 35 & 76 & \\
\hline 8 & 390 & 769 & 1154 & 0.4 & 1.27 & 23.4 & 35 & 60 & \\
\hline 9 & 390 & 762 & 1143 & 0.4 & 2.54 & 46.8 & 35 & 66 & \\
\hline 10 & 356.4 & 650 & 1260 & 0.42 & 5.4 & 3.6 & 10 & 66.36 & \multirow[t]{2}{*}{ Mao-hua Zhang et al. (2011) } \\
\hline 11 & 349.2 & 650 & 1260 & 0.42 & 7.2 & 10.8 & 10 & 61.16 & \\
\hline 12 & 447.75 & 492 & 1148 & 0.4 & 0 & 2.25 & 80 & 39.2 & \multirow[t]{10}{*}{ Alireza Naji Givi et al. (2010) } \\
\hline 13 & 445.5 & 492 & 1148 & 0.4 & 0 & 4.5 & 80 & 40.3 & \\
\hline 14 & 443.25 & 492 & 1148 & 0.4 & 0 & 6.75 & 80 & 41.2 & \\
\hline 15 & 441 & 492 & 1148 & 0.4 & 0 & 9 & 80 & 38.1 & \\
\hline 16 & 447.75 & 492 & 1148 & 0.4 & 0 & 2.25 & 15 & 42.7 & \\
\hline 17 & 445.5 & 492 & 1148 & 0.4 & 0 & 4.5 & 15 & 43.6 & \\
\hline 18 & 443.25 & 492 & 1148 & 0.4 & 0 & 6.75 & 15 & 42.9 & \\
\hline 19 & 441 & 492 & 1148 & 0.4 & 0 & 9 & 15 & 39.7 & \\
\hline 20 & 394 & 811 & 915 & 0.45 & 1.68 & 12 & 15 & 53.8 & \\
\hline 21 & 388 & 811 & 915 & 0.45 & 2.32 & 24 & 15 & 56.5 & \\
\hline 22 & 382 & 811 & 915 & 0.45 & 3 & 36 & 15 & 60 & M.Nili et al. (2010) \\
\hline 23 & 247.5 & 625 & 0 & 0.5 & 4.5 & 7.5 & 40 & 54.3 & \multirow[t]{4}{*}{ Byung Wan Jo et al. (2007) } \\
\hline 24 & 240.6 & 626 & 0 & 0.5 & 5.8 & 14.4 & 40 & 61.9 & \\
\hline 25 & 241.8 & 627 & 0 & 0.5 & 7 & 23.2 & 40 & 68.2 & \\
\hline 26 & 227.7 & 628 & 0 & 0.5 & 7.5 & 27.3 & 40 & 68.8 & \\
\hline 27 & 370 & 647 & 1088 & 0.49 & 13.5 & 13.9 & 15 & 44 & Tao Ji et al. (2005) \\
\hline 28 & 568.36 & 1757.8 & 0 & 0.5 & 8.85 & 17.5 & 15 & 32.9 & \multirow[t]{4}{*}{ Hui Li et al. (2004) } \\
\hline 29 & 556.64 & 1757.8 & 0 & 0.5 & 14.58 & 29.3 & 15 & 33.8 & \\
\hline 30 & 527.34 & 1757.8 & 0 & 0.5 & 29.3 & 58.59 & 15 & 36.4 & \\
\hline 31 & 556.64 & 1757.8 & 0 & 0.5 & 10.28 & 11.71 & 15 & 35.4 & \\
\hline 32 & 480 & 647 & 1140 & 0.28 & 10 & 20 & 10 & 75.8 & Gengying Li (2004) \\
\hline
\end{tabular}

Note: All type of SP have been considered to be same. 


\section{Database}

The database for the various models was collected from available literature on concrete containing nano-silica, as summarized in Table 1. The success of the models depends upon the comprehensiveness of the data. Thus, large varieties of data were collected and in total 32 datasets have been used with the following input and output variables. The basic parameters considered in this study were cement content, fine aggregate content, coarse aggregate content, nano-silica content, diameter of nano-silica, water-to-binder ratio and superplasticizer dosage. The exclusion of one or more of concrete properties in some studies and the ambiguity of mixtures proportions and testing methods in others was responsible for setting the criteria for identification of data. The successful model to predict the 28 days compressive strength depends upon the magnitude of the training data. The predicted results were compared with the values obtained experimentally.

The variables used are as follows:

Cement

FA (fine aggregates)

CA (coarse aggregates)

$\mathrm{W} / \mathrm{b}$ ratio

SP (superplasticizer)

$\mathrm{nS}$ (nano-silica)

Diameter of nano-silica

The ranges of various input and the output parameters used in data mining techniques are given in Tables 2 .

\section{Application of ANN Techniques}

The multilayer perceptron with back propagation approach has been used for the modelling in ANN technique. Back propagation is common method of training artificial neural networks so as to minimize the objective function. It is a supervised learning method and a generalization of the Delta rule. The activation function used is the log-sigmoidal function. A sigmoid curve is produced by a mathematical function having an "S" shape. Often, sigmoid function refers to the special case of the logistic function shown in Figure 1 and defined by the formula:

$$
\mathrm{S}(\mathrm{t})=1 /\left(1+\mathrm{e}^{-\mathrm{t}}\right)
$$

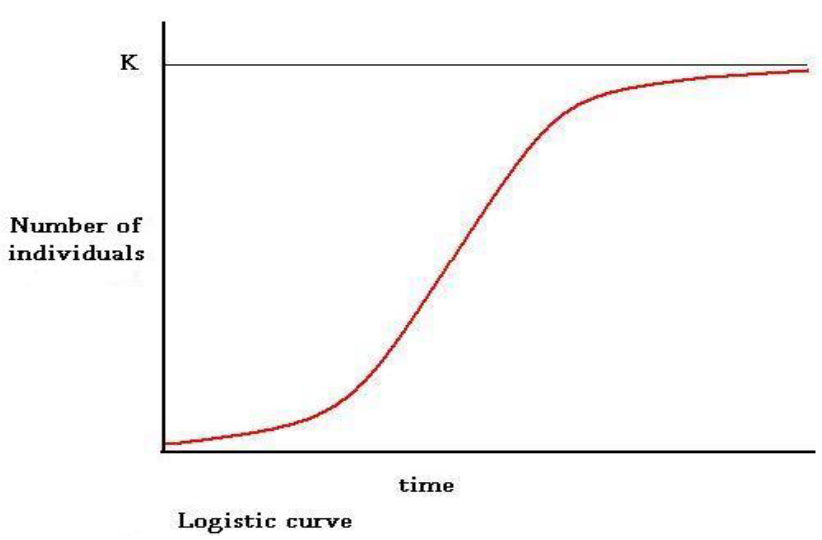

Figure 1. Logistic Curve

The test mode which is used in this model is 10-fold cross-validation. In $\mathrm{k}$-fold cross-validation, the original sample is randomly partitioned into $\mathrm{k}$ subsamples. Of the $\mathrm{k}$ subsamples, single sub sample is retained as the validation data for testing the model, and the remaining $\mathrm{k}-1 \mathrm{sub}$ samples are used as training data. The cross-validation process is then repeated $\mathrm{k}$ times (the folds), with each of the $\mathrm{k}$ subsamples used exactly once as the validation data. The $\mathrm{k}$ results from the folds then can be averaged (or otherwise combined) to produce a single estimation. This neural network uses back propagation to train.

Table 2. Input and Output variables

\begin{tabular}{|c|c|c|c|c|}
\hline \multirow{2}{*}{ Variables } & \multirow{2}{*}{ Parameter } & \multirow{2}{*}{ Abbreviation } & \multicolumn{2}{|c|}{ Database Range } \\
\hline & & & Minimum & Maximum \\
\hline \multirow{7}{*}{ Input } & Cement (kg/m3) & Cement & 227.70 & 568.36 \\
\hline & Fine aggregate $(\mathrm{kg} / \mathrm{m} 3)$ & FA & 492 & 1757.80 \\
\hline & Coarse aggregate $(\mathrm{kg} / \mathrm{m} 3)$ & $\mathrm{CA}$ & 0 & 1260 \\
\hline & Water to binder ratio & $\mathrm{W} / \mathrm{b}$ ratio & 0.28 & 0.50 \\
\hline & Super Plasticizer (kg/m3) & SP & 0 & 29.30 \\
\hline & Nano-silica (kg/m3) & $\mathrm{nS}$ & 1.60 & 58.59 \\
\hline & Diameter of nano-silica (nm) & $\mathrm{D}$ & 10 & 80 \\
\hline Output & 28 days Compressive Strength (MPa) & 28-d CS & 32.90 & 86.10 \\
\hline
\end{tabular}

The procedure for determining the output from the inputs is as given: 
1. Sum up weighted inputs, i.e.

$$
\text { Nodj } \quad={ }_{\mathrm{i}=1}^{\mathrm{IN}} \sum\left(\mathrm{W}_{\mathrm{ij}} \mathrm{x}_{\mathrm{i}}\right)
$$

Where; Nodj is summation for jth-hidden node, IN is total number of input nodes, $\mathrm{W}_{\mathrm{ij}} \quad$ is connection weight $\mathrm{i}^{\text {th }}$ input and $\mathrm{j}^{\text {th }}$ hidden node,

$\mathrm{x}_{\mathrm{i}} \quad$ is normalized input at $\mathrm{i}^{\text {th }}$ input node.

2. Transform the weighted input:

$$
\text { Out }_{\mathrm{j}}=1 /\left(\mathrm{C}^{-\mathrm{Nodj}}\right)
$$

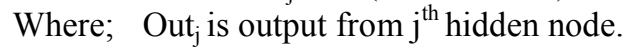

3. Sum up the hidden node outputs:

$$
\operatorname{Nod}_{k}={ }_{j=1}^{H N} \sum\left(\begin{array}{ll}
W_{j k} & \text { Out } \left._{j}\right)_{k}
\end{array}\right.
$$

Where; $\quad \operatorname{Nod}_{\mathrm{k}}$ is summation for $\mathrm{k}^{\text {th }}$ output node,

$\mathrm{HN}$ is total number of hidden nodes, hidden and $\mathrm{k}^{\text {th }}$ output node.

$\mathrm{W}_{\mathrm{jk}} \quad$ is connection weight between $\mathrm{jth}$

4. Transform the weighted sum:

$$
\text { Out }_{\mathrm{k}}=1 /\left(1+\mathrm{e}^{- \text {-Nodj }}\right)
$$

Where; Out ${ }_{k}$ is output at $k^{\text {th }}$ output node.

Back propagation method of training of ANN has been done. From a desired output, the network learns from many inputs. It is a supervised learning method, and is a generalization of the delta rule. The learning rate is a common parameter in many of the learning algorithms, and affects the speed at which the ANN arrives at the minimum solution. In back propagation, the learning rate is analogous to the step-size parameter from the gradient-descent algorithm. The momentum parameter is used to prevent the system from converging to a local minimum or saddle point. A high momentum parameter can also help to increase the speed of convergence of the system. The normalization of the data had been done by using the software WEKA used in carrying out the ANN analysis. In the pre-process, the minimum, maximum, mean and standard deviation for each feature is computed and used in the sigmoidal function transformation. This maintains the resolution of most values that are within a standard deviation of the mean. Thus, it puts the normalized data in a range of 0 to 1 . The cross-validation technique with 10 folds has been carried out which is a standard tool in analytics and is an important feature for helping one develop and fine-tune the data mining models

\section{Test Results}

The acceptance or rejection of the model developed is determined by its ability to predict the 28 days compressive strength of the mix used. The correlation coefficient $\left(\mathrm{C}_{\mathrm{c}}\right)$, root mean square error (RMSE), and mean absolute error (MAE) is used to judge the performance of the neural network approach in predicting the results. Since the neural networks are trained on actual test data, they are trained to deal with inherent noisy or imprecise data. As new data become available, the neural network model can be readily updated by retraining with patterns which include these new data. It is clearly seen from the Figure 2 the flowchart of the Multi-layer perceptron used in back propagation technique in the study. From Figure 3, the results suggest that most of the points are lying within $\pm 20 \%$ of the line of perfect agreement, which suggest that neural network, can effectively be used to predict the strengths. There is a wide variation in some of the data which can be omitted and also further scope of data mining techniques can be used such as fuzzy logic approach.

\section{Conclusions}

In the present study, the ANN model for 28-day compressive strength has been developed. The model was trained with input and output experimental data. Correlation coefficient, RMSE and MAE are statistical values that are calculated for comparing experimental data with ANN model. As a result, compressive strength values of concrete can be predicted in ANN models without attempting any experiments in a quite short period of time with some error rates which can be minimized further by using other data mining techniques such as M5 method, fuzzy logic techniques, etc. Table 3 indicates the actual and predicted values of 28 days compressive strength by using ANN technique. Table 4 gives the statistical parameters while Figure 4 gives the actual v/s predicted results of the 28-d compressive strength using ANN technique. Hence the correlation coefficient was found to be 0.8685 . 


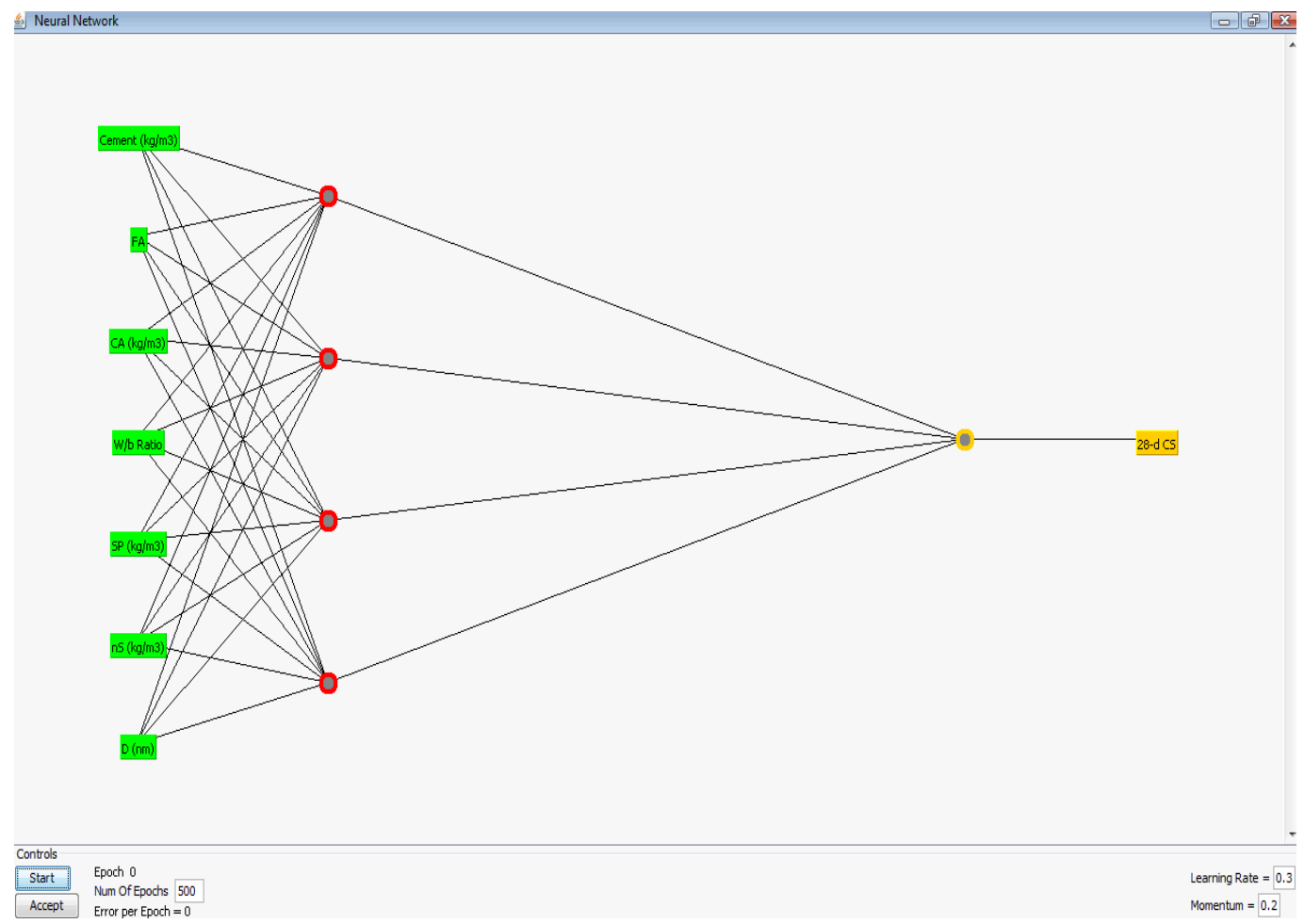

Figure 2. Flowchart of MLP used in the study

Table 3. Actual and Predicted values of 28 days compressive strength using ANN technique

\begin{tabular}{|c|c|c|c|}
\hline S.No. & Actual 28-d CS (MPa) & Predicted 28-d CS (MPa) & Error \\
\hline 1 & 75.2 & 78.325 & 3.125 \\
\hline 2 & 86.1 & 79.619 & -6.481 \\
\hline 3 & 85.4 & 95.909 & 10.509 \\
\hline 4 & 36.8 & 48.961 & 12.161 \\
\hline 5 & 40.2 & 43.085 & 2.885 \\
\hline 6 & 70 & 58.949 & -11.051 \\
\hline 7 & 76 & 69.969 & -6.031 \\
\hline 8 & 60 & 59.152 & -0.848 \\
\hline 9 & 66 & 71.429 & 5.429 \\
\hline 10 & 66.36 & 51.074 & -15.286 \\
\hline 11 & 61.16 & 59.938 & -1.222 \\
\hline 12 & 39.2 & 36.233 & -2.967 \\
\hline 13 & 40.3 & 50.053 & 9.753 \\
\hline 14 & 41.2 & 42.562 & 1.362 \\
\hline 15 & 38.1 & 38.116 & 0.016 \\
\hline 16 & 42.7 & 50.132 & 7.432 \\
\hline 17 & 43.6 & 39.725 & -3.875 \\
\hline 18 & 42.9 & 43.161 & 0.261 \\
\hline 19 & 39.7 & 51.405 & 11.705 \\
\hline 20 & 53.8 & 42.389 & -11.411 \\
\hline 21 & 56.5 & 58.198 & 1.698 \\
\hline 22 & 60 & 59.152 & -0.848 \\
\hline 23 & 54.3 & 52.123 & -2.177 \\
\hline 24 & 61.9 & 62.075 & 0.175 \\
\hline 25 & 68.2 & 62.135 & -6.065 \\
\hline 26 & 68.8 & 71.317 & 2.517 \\
\hline 27 & 44 & 36.241 & -7.759 \\
\hline 28 & 32.9 & 35.474 & 2.574 \\
\hline 29 & 33.8 & 26.247 & -7.553 \\
\hline 30 & 36.4 & 62.96 & 26.56 \\
\hline 31 & 35.4 & 34.122 & -1.278 \\
\hline 32 & 75.8 & 77.278 & 1.478 \\
\hline
\end{tabular}

Table 4. Statistical parameters 


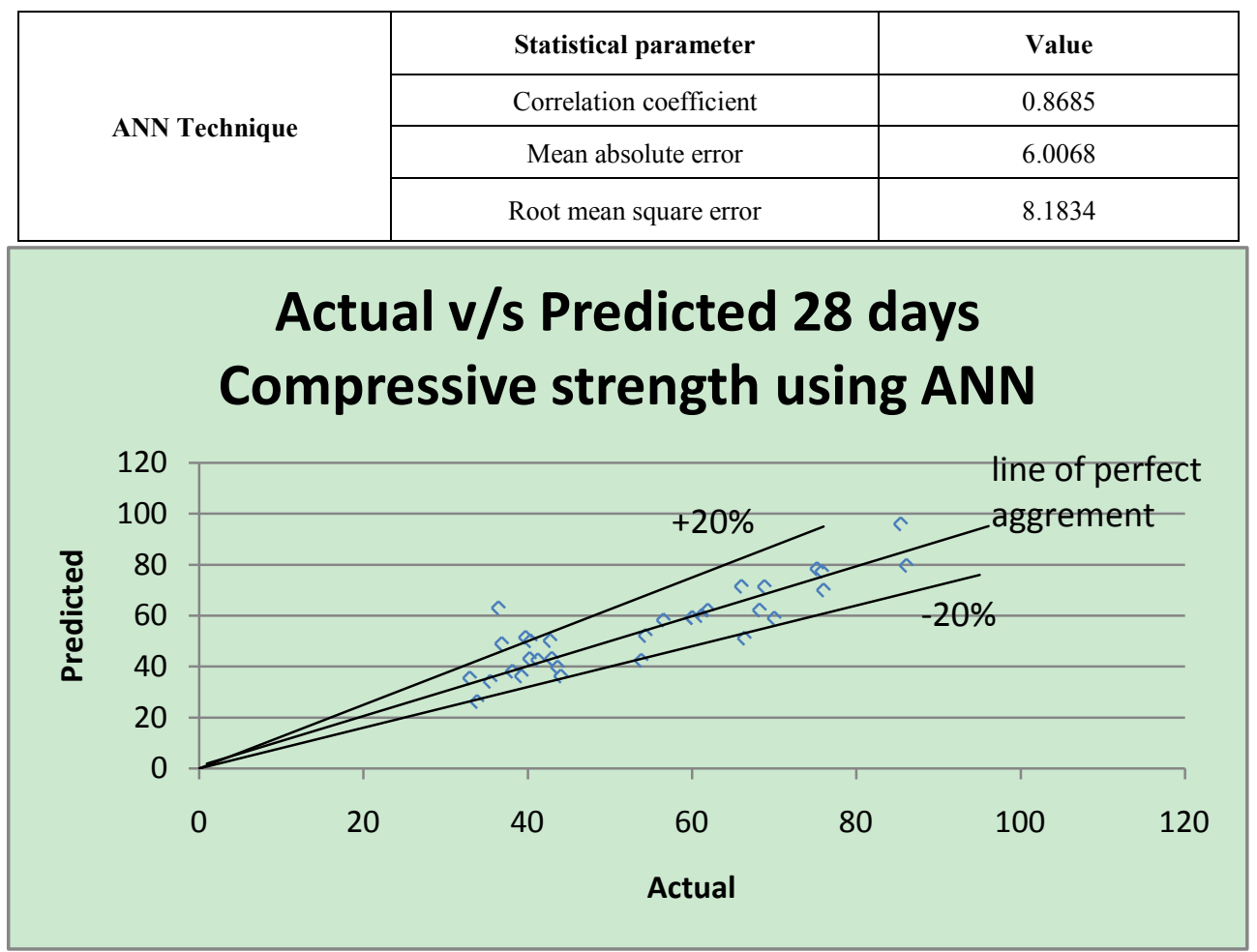

Figure 3. Results comparison with line of perfect agreement

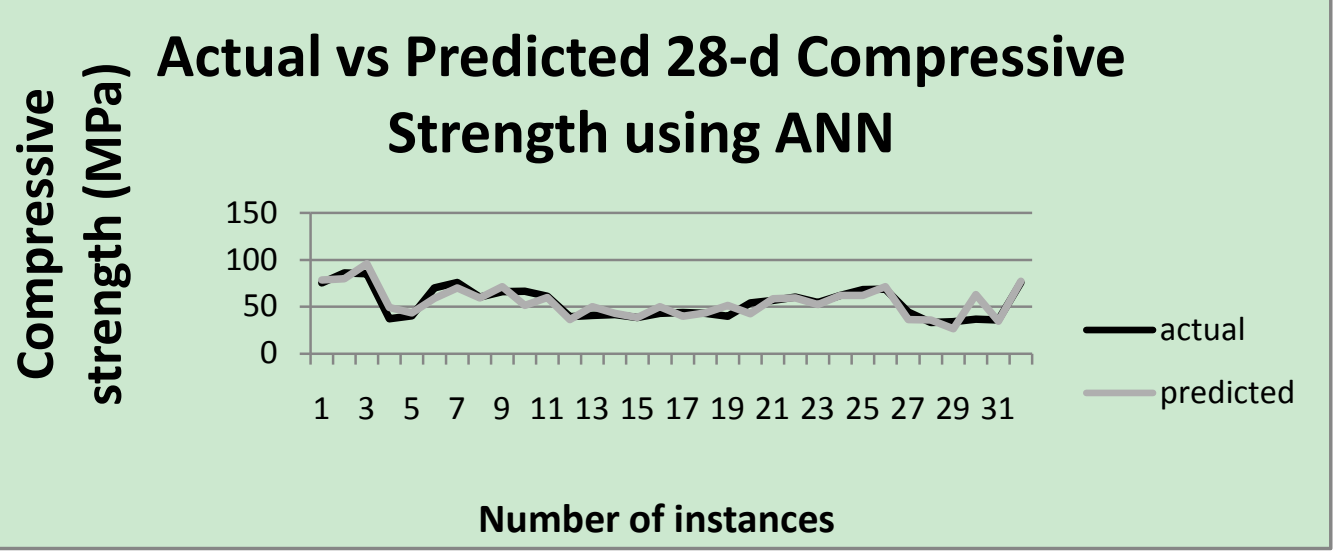

Figure 4. Actual v/s Predicted results of the 28-d compressive strength using ANN technique.

\section{REFERENCES}

[1] Aitcin, P. C. Hershey, P.A., and Pinsonneault. Effect of the addition of condensed silica fume on the compressive strength of mortars and concrete, American Ceramic Society. 22:286-290; 1981.

[2] ARI News. Nanotechnology in Construction - One of the Top Ten Answers to World's Biggest Problems. www.aggregateresearch.com/article. id=6279; June 2007.

[3] S. Akkurt, G. Tayfur, and S. Can, Fuzzy logic model for prediction of cement compressive strength, Cement Concr Res, 2004, 34(8), pp.1429-1433.

[4] O. Unal, F. Demir, and T. Uygunog $`$ lu, Fuzzy logic approach to predict stress-strain curves of steel fiber-reinforced concretes in compression, Build Environ 2007, 42(10), pp. 3589-3595.

[5] F. Demir, A new way of prediction elastic modulus of normal and high strength concrete-fuzzy logic, Cement Concr Res, 2005, 35(8), pp.1531-1538.

[6] I.B. Topcu, and M. Sarıdemir, Prediction of mechanical properties of recycled aggregate concretes containing silica fume using artificial neural networks and fuzzy logic, Comput Mater Sci, 2008, 42(1), pp.74-82.

[7] Beigi Morteza H., Berenjian Javad, Omran Omid Lotfi, Nik Aref Sadeghi, Nikbin Iman M.(2013). An experimental survey on combined effects of fibers and nanosilica on the mechanical, rheological, and durability properties of self-compacting concrete. Materials \& Design ; 50: 
$1019-1029$.

[8] Jo B.W., Kim C.H., Tae G., Park J.B. (2007). Characteristics of cement mortar with nano- $\mathrm{SiO} 2$ particles. Construction and Building Materials; 21(6):1351-5.

[9] Li G. (2004) Properties of high-volume fly ash concrete incorporating nano-SiO2. Cement and Concrete Research; 34(6):1043-9.

[10] Said A.M., Zeidan M.S., Bassuoni M.T., Tian Y. (2012). Properties of concrete incorporating nano-silica. Construction and Building Materials; 36: 834-44.

[11] Mao-hua Zhang and Hui Li b, "Pore structure and chloride permeability of concrete containing nano-particles for pavement". Construction and Building Materials 25 (2011) @ Elsevier Ltd. pp. 608-616.

[12] Tao Ji (2005). Preliminary study on the water permeability and microstructure of concrete incorporating nano-SiO2".
Cement and Concrete Research; 35:943-47.

[13] Ali Heidari, Davoud Tavakoli (2013). A study of the mechanical properties of ground ceramic powder concrete incorporating nano-SiO2 particles. Construction and Building Materials; 38: 255-64.

[14] Alireza Naji Givi, Suraya Abdul Rashid, Farah Nora A. Aziz, Mohamad Amran Mohd Salleh(2010). Experimental investigation of the size effects of $\mathrm{SiO} 2$ nano-particles on the mechanical properties of binary blended concrete. Composites: Part B; 41: 673-77.

[15] Nili M., Ehsani A., and Shabani K. (2010). Influence of Nano-SiO2 and Micro-silica on Concrete Performance. Second International Conference on Sustainable Construction Materials and Technologies.

[16] Li H., Gang H., Jie X., Yuan J., Ou J. (2004). Microstructure of cement mortar with nanoparticles. Composites Part B: Engineering; 35(2):185-9 